Cuestiones de filosofía

ISSN: 0123-5095

Vol. 1 - No. 17

Año 2015

pp. $139-162$

\title{
FOUCAULT Y LA AUFKLÄRUNG, O EL TRABAJO DE SÍ COMO LEGADO CRÍTICO
}

\author{
Foucault and the Aufklärung, or the \\ work of oneself as a critical legacy
}

\author{
Pablo Martín-Méndez* \\ pablomartínmendez@hotmail.com \\ Comisión de Investigaciones Científicas de la Provincia de Buenos Aires
}

(Argentina)

Fecha de recepción: 1/03/ 2015

Fecha de evaluación: 1/04/2015

Fecha de aprobación: 7/09/2015

\section{Resumen}

El pensamiento de Michel Foucault parecería dirimirse entre tres dimensiones específicas, aunque no necesariamente excluyentes, esto es: el saber, el poder y la subjetivación. Si bien se ha dicho bastante sobre el modo como ese pensamiento pasa desde la primera dimensión a la segunda, restaría observar todavía cómo devino tridimensional; en otras palabras, hay que preguntar cómo fue posible no la concepción del poder, sino la salida de todo el enredo al que condujo una concepción semejante. Así pues, y tal como señala este artículo, la salida partirá desde la respuesta ante la cuestión Was ist Aufklärung? [¿Qué es la Ilustración?]. Precisamente aquí, en la Aufklärung como interrogación crítica sobre el presente, Foucault encuentra la posibilidad de franquear los límites del poder. Se trata de todo un "trabajo nuestro sobre nosotros mismos"; se trata también de abrir el "gobierno de sî" entre el "gobierno de los otros".

* Licenciado y Profesor de Enseñanza Media y Superior en Ciencia Política por la Universidad de Buenos Aires, Doctorando en Filosofía por Universidad Nacional de Lanús, y Becario doctoral de la Comisión de Investigaciones Científicas de la Provincia de Buenos Aires (Argentina).pablomartínmendez@ hotmail.com 
Ahora bien, la actitud crítica de la Aufklärung puede llevarse aún más lejos, tanto como para aplicarla sobre los modos en que actualmente intentamos gobernarnos a nosotros mismos. Según sostiene el artículo en su parte final, es justamente eso lo que hacía Foucault cuando abordaba la cuestión del "neoliberalismo". Antes que una mera ideología económica, el neoliberalismo emerge como toda una relación de sí consigo mismo; de ahí el legado que nosotros recibimos hoy de Foucault: para franquear los límites de aquello que ya somos, para ser otros que nosotros mismos, debemos hacer una profunda y comprometida crítica de la subjetividad neoliberal.

Palabras clave: Foucault, Ontología del presente, Gobierno de sí y Gobierno de los otros, Neoliberalismo.

\begin{abstract}
Michel Foucault's thought would seem to be distributed among three specific dimensions although not necessarily exclusives, i.e., the "knowledge", the "power" and the "subjectivity". While enough has been said about how that thought goes from the first dimension to the second, it would remain still to observe how the same one became three-dimensional; in other words, it is necessary to ask not the power conception, but how was possible the exit of the whole dilemma that led the Foucault's conception of power. Therefore, and as this article will indicate, the output will start from the response to the question Was ist Aufklärung? ¿What is Ilustration? Precisely here, in the Aufklärung as critical interrogation on the present, Foucault finds the possibility of going beyond the limits of power. It is an issue of our "work on ourselves"; it is also about opening the "government of oneself" between the "government of others".

Now then, the critical attitude of the Aufklärung can be taken even further, as well as to apply on the ways in which we are currently trying to govern ourselves. As this article will support in its final part, it is exactly what Foucault did when he was tackling the question of the "neoliberalism". Rather than a mere economic ideology, the neoliberalismemerged as an entire other relationship of the individual with himself. That is the legacy that we received today from Foucault: to penetrate the limits of what we already are, we must make a deep and committed critique to the neoliberal subjectivity.
\end{abstract}

Keywords: ontology of the present, government of self and government of others, public, neoliberalism. 


\section{INTRODUCCIÓN}

En cierta ocasión, alguien advirtió que el pensamiento de MichelFoucault procede a través de grandes crisis y conmociones; como si en lugar de constituir un sistema tranquilo y equilibrado, se asemejase más a una impredecible cadena volcánica ${ }^{1}$. El modo como Foucault experimentaba y llevaba adelante el pensamiento tenía, efectivamente, muy poco de sistemático; diríase más bien que allí todo se desgarra y desdobla, que los intentos de unidad y de síntesis se tornan meramente provisorios, una y otra vez prestos a ceder por la fragilidad del suelo que pisan. Cada conmoción brindaría el testimonio de algo imprevisible e insondable; algo que avanza subterráneamente, siempre en silencio, para irrumpir al final con suma violencia.

Ir de crisis en crisis, pero también de silencio en silencio, ¿acaso no sería esta una posible manera de pensar? Por supuesto, no se trata de un plan perfectamente meditado, ni de una guía para usar el pensamiento correctamente. Antes bien, la cuestión consiste en avanzar a fuerza del error y del desequilibrio: "si se admite que el concepto es la respuesta que la vida le da al azar, debemos convenir que el error es la raíz del pensamiento humano y de su historia" (Foucault, 2007, p. 56). Fue así como Foucault habría pensado durante gran parte de su vida; más aún en los últimos años, cuando "una crisis le afectó en todos los terrenos, en el político, en el vital y en el del pensamiento. Como sucede con todos los grandes pensadores, su pensamiento se servía de crisis y conmociones como condición creativa, como condición de coherencia última" (Deleuze, 2002, p. 97). Una crisis, un silencio, justamente entre las tres dimensiones del pensamiento de Foucault: el que se da a pensar el "saber" y, luego, el "poder"; el que pasa por los regímenes de saber-poder para terminar en las prácticas y los procesos de "subjetivación".

El propio Foucault ha hablado en más de una oportunidad sobre las crisis que lo condujeron desde la dimensión del saber hacia la dimensión del poder ${ }^{2}$. Pues bien,

1 Estamos parafraseando a Gilles Deleuze: "La lógica de un pensamiento es el conjunto de las crisis que atraviesa, se parece más a una cordillera volcánica que a un sistema tranquilo y aproximadamente equilibrado. (...) tengo la impresión de que esta lógica de Foucault, estas transiciones, estos impulsos no se comprendieron bien“ (2002, p. 97). Durante la redacción del presente artículo, nosotros nos hemos inspirado en muchas observaciones de Deleuze, todas ellas tan concisas como esclarecedoras.

2 La crisis se anunciaba ya en La arqueología del saber, que sale a la luz en 1969 y que constituye, sin duda, un libro puente entre las mencionadas dimensiones: "no estoy donde ustedes tratan de describirme, sino aquí, de donde los miro, riendo. (...) 
tal vez ahora valga la pena preguntar por las condiciones en que el pensamiento de Foucault devino efectivamente tridimensional; en otras palabras, convendría recorrer las crisis y los silencios que mediaron entre la dimensión del poder y los modos de subjetivación. Nosotros retomaríamos aquí el gran interrogante de Deleuze: “Qué ha pasado durante el largo silencio que ha seguido a La voluntad de saber? Quizá Foucault tiene la sensación de que ese libro va unido a cierto malentendido: ¿no se ha encerrado en las relaciones de poder?" (Deleuze, 2008, p. 125) ${ }^{3}$. Ya se tratase de un malentendido o no, es de destacar el hecho de que la pregunta de Deleuze continúe con la cita de una famosa objeción, esta vez planteada por el mismo Foucault: "he aquí de nuevo la incapacidad para franquear la frontera, para pasar del otro lado (...), siempre la misma opción de contemplar la cara iluminada del poder, lo que dice o lo que hace decir" (Deleuze, 2008, p. 125; Foucault, 2008a, p. 124). De donde se desprende el objetivo del presente artículo. Se trata de un objetivo de dos caras: primero, y ante todo, consiste en precisar cómo y desde qué lugar resultó posible no la concepción foucaultiana del poder, sino la salida de todo el enredo al que condujo una concepción semejante; pero también, y un poco más allá de esta cuestión puntual, se intenta vislumbrar aquello que emerge en el mismo camino de salida, aquello que recibimos nosotros, los que pensamos con Foucault y desde de Foucault.

Más de uno, como yo sin duda, escriben para perder el rostro. Ni me pregunten quién soy, ni me pidan que permanezca invariable: es una moral de estado civil la que rige nuestra documentación. Que nos deje en paz cuando se trata de escribir" (2002, p. 30). En 1977, durante una entrevista publicada posteriormente como "Verdad y poder", Foucault señalaría los diferentes sucesos que lo impulsaron a modificar su concepción del poder, especialmente la que aparecía de manera implícita en la Historia de la locura y en El nacimiento de la clínica: "Cuando lo pienso de nuevo, ahora, me pregunto, ¿de qué he podido hablar, por ejemplo, en la Historia de la locura o en El nacimiento de la clínica, si no era del poder? Pero soy perfectamente consciente de no haber prácticamente empleado el término y de no haber tenido este campo de análisis a mi disposición. Puedo decir que ciertamente existía una incapacidad que estaba ligada con toda seguridad a la situación política en que nos encontrábamos" (1992, p. 190). Ocurre que el poder se concebía principalmente en términos "negativos", más como una fuerza represiva que productiva. Hubo que esperar hasta Vigilar y castigar, y sobre todo La voluntad de saber, para que Foucault modificase completamente esa concepción tan limitada.

3 Sobre la recepción de La voluntad de saber, ténganse además en cuenta la crónica recogida por Didier Eribon: "el libro tiene una acogida que Foucault tacha de moderada y reservada. Quiso ir a contracorriente, asestar un golpe frontal a las ideas dominantes de la 'actualidad', decir a unos y otros la verdad histórica de sus gestos y sus palabras (...). Sin embargo, percibe en todas partes en su entorno una cierta decepción (...). Foucault experimenta la amarga sensación de haber sido mal leído, mal comprendido. Mal querido, tal vez" (1992, pp. 339-340).

142 Cuestiones de Filosofía No. 17 - Vol. 1 A ño 2015 ISSN 0123-5095 Tunja-Colombia 


\section{LA AUFKLÄRUNG, LA SALIDA}

Durante el largo silencio -que es ciertamente, y como ya se sabe, un silencio en la publicación de libros, mas no en la concesión de conferencias y de entrevistas, la redacción de artículos y prefacios, sumado a los memorables cursos brindados en el Collège de France-Foucault buscará una suerte de salida ${ }^{4}$. De más está decir aquí que Foucault saldrá del problema a su modo, con ese movimiento instintivo tan propio y a la vez tan ajeno, como si fuese un cangrejo que traza diagonales subterráneas y emerge luego en los lugares menos previsibles. Así pues, la salida se traza desde la respuesta o, más bien, desde la serie de respuestas, ante una cuestión sumamente precisa, a saber: Was ist Aufklärung? [¿Qué es la Ilustración?]. Cuestión que irrumpiría hacia fines del siglo XVIII y cuyo planteamiento directo resultaría para Foucault "imprudente": "En un principio, esta pregunta fue relativamente accesoria: se interrogaba a la filosofía acerca de la forma que podía tomar. Aunque rápidamente se reveló que las respuestas que se daban amenazaban seriamente con ir más allá" (2007, p. 44). Cierto es que Foucault querrá asociarse en adelante a esas respuestas; más aún, todo su trabajo consistirá ahora en llevar la cuestión de la Aufklärung hasta una frontera insospechada.

Pero retomemos en todo caso el planteamiento de partida, Was ist Aufklärung? A fines del siglo XVIII, Kant se encargaría de brindar una de las primeras y, de seguro, más célebres respuestas: "La Ilustración es la salida del hombre de su autoculpable minoría de edad" (2005, p. 21). La Ilustración señala una salida [Ausgang], y no un momento concatenado a otros momentos; implica asimismo una ruptura, antes que el anuncio de un acontecimiento próximo; es, si se quiere, un desenlace, más que el punto de transición hacia un estado de mayor perfección. Al menos de esta manera lo entendería Foucault: "aquello que Kant designa como el momento de la Aufklärung no es ni una pertenencia, ni una inminencia, ni una consumación, ni siquiera un pasaje (...). Kant se limita a definir el momento presente

4 Recordemos que Foucault volverá a ocupar la cátedra "Historia de los sistemas de pensamiento", del Collège de France, en 1978, luego de haberse tomado todo un año sabático. A partir de entonces y hasta su muerte, dictará sucesivamente los cursos Sécurité, territoire, population (1978), Naissance de la biopolitique (1979), Du gouvernement des vivants (1980), Subjectivité et vérité (1981), L'Herméneutique du sujet (1982), Le gouvernement de soi et des autres (1983) y Le courage de la vérité (1984). Desde los últimos diez años, estos cursos vienen siendo traducidos al castellano por las editoriales Akal y Fondo de Cultura Económica. Para elaborar el presente artículo, nosotros nos hemos centrado especialemente en los cursos de 1979 y 1983. 
como Ausgang, desenlace, salida, movimiento por el cual nos desprendemos de algo, sin que nada se diga sobre el lugar hacia donde vamos" (2011, p. 43). Se trataría de otro modo de concebir el presente, ya no en función de una totalidad o de una realización futura, tampoco como signo de un acontecimiento inminente, sino como momento diferente, momento de salida.

El presente difiere por un conjunto de razones complementarias o, más bien, por la manera como se aborda la cuestión primera: Was ist Aufklärung? Con cierta anterioridad, las preguntas sobre el presente concernían por entero al orden del conocimiento: "cuando Descartes, en el Discurso del método, cuenta su propio itinerario y el conjunto de decisiones filosóficas que ha tomado (...), se refiere (...) a lo que puede considerarse como una situación histórica en el orden del conocimiento, de las ciencias, de la institución misma del saber en su propia época" (Foucault, 2011, p. 29). Pero a partir de Kant, y más fundamentalmente de ese pequeño escrito que aborda la cuestión Was ist Aufklärung?, las cosas cambian. Más que interrogar la situación actual del conocimiento, se plantea la situación de un nosotros histórico; de nosotros precisamente aquí, en el momento presente, formando parte de esto que ha dado en llamarse Aufklärung. Toda una cuestión viene a agregarse a la de antaño: "Kant pregunta algo distinto: ¿quiénes somos, en este momento preciso de la historia? La pregunta de Kant aparece como un análisis tanto de nosotros mismos como de nuestro presente. Creo que este aspecto de la filosofía adquirió cada vez más importancia. Pensemos en Hegel, en Nietzsche..." (Foucault, 1988, p. 10). Al presente como motivo para una decisión hasta entonces más importante, la decisión sobre el conocimiento, hay que agregarle en adelante el nosotros. Nótese la diferencia: lo que se plantea como pregunta no es el presente o el nosotros considerados aisladamente; por el contrario, es nuestro presente, aquel en el cual nos encontramos y desde el cual hablamos.

A partir del momento en que se planteara la cuestión Was ist Aufklärung?, la actividad filosófica tendería a repartirse entre dos tradiciones distintas, aunque no necesariamente excluyentes. La primera de ellas observa y determina las condiciones de posibilidad para el conocimiento verdadero: "todo un sector de la filosofía moderna, durante el siglo XIX, se presentó, se desarrolló como analítica de la verdad. Es el tipo de filosofía que vamos a reencontrar ahora bajo la forma de la filosofía analítica anglosajona" (Foucault, 2011, p. 38). La corriente restante pertenecería, sin embargo, a otra suerte de repartición; ante todo, porque sus preguntas no plantearán una suerte de analítica, no irán tras el ser universal y ahistórico de la verdad, sino que más bien permanecerán referidas a un momento singular. 
De preguntar por las condiciones de verdad para este mundo y para todos los mundos posibles, la actividad filosófica pasa a interrogar lo que somos nosotros actualmente, en la particularidad de nuestro tiempo. Interrogar lo que somos o, también, hacer el tipo de filosofía que Foucault denominaba "ontología del presente": "se trataría de (...) una ontología del presente, una ontología de la actualidad, una ontología de la modernidad, una ontología de nosotros mismos. (...) Esta forma de filosofía, de Hegel hasta la Escuela de Fráncfort, pasando por Nietzsche, Max Weber, etcétera, ha fundado un tipo de reflexión al cual me asocio en la medida de mis posibilidades" (2011, p. 39). Cuestión del presente, cuestión del nosotros, y en suma, de asociarse a otro modo de actividad filosófica.

Luego de enfrentar la cuestión Was ist Aufklärung?, Kant señala una salida; más tarde, y atravesando la salida, Foucault habrá de asociarse a una nueva lógica de repartición. Durante el paso van quedando atrás ciertas divisiones; en principio, y por encima de todo, las que limitan el propio quehacer filosófico. Como bien indicará Foucault: que la Aufklärung defina un nuevo modo de filosofar, que a partir de entonces emerja una reflexión acerca de nuestros mismos y de nuestro presente, no implica ni tiene por qué implicar que debamos colocarnos en favor de aquella. La cuestión consiste en salir de todo lugar donde el único dilema sea estar a favor o en contra de la Aufklärung, incluyendo aquí su desarrollo histórico y, más fundamentalmente, su forma de racionalidad ${ }^{5}$. Antes que plantear alternativas demasiado simples o de chantajear al pensamiento para que asuma una posición predeterminada, se debería hacer la prueba de filosofar en los límites de la Aufklärung: "las investigaciones no estarán orientadas retrospectivamente hacia el 'núcleo esencial de racionalidad' que puede encontrarse en la Aufklärung y que sería preciso salvaguardar a toda costa; estarán orientadas hacia 'los límites actuales de lo necesario', es decir, hacia lo que no es o ya no resulta indispensable para la constitución de nosotros mismos como sujetos autónomos" (Foucault, 1999b, p. 346). Ni a favor ni en contra de la Aufklärung, sino en sus fronteras.

5 Según señalara Foucault en varias ocasiones, el desafío pasaría por evitar la persistente dicotomía entre el "racionalismo" y el "irracionalismo”: “¿Debemos juzgar a la razón? A mi modo de ver, nada sería más estéril. (...) semejante proceso nos induciría a engaño al obligarnos a adoptar el papel arbitrario y aburrido del racionalista o irracionalista" (2008c, pp. 96-97). Foucault retomaría la misma idea en la entrevista titulada "Estructuralismo y posestructuralismo"; de hecho, allí remarcará el "chantaje" en el cual cae cualquier interrogación crítica sobre la historia de la racionalidad. Dicho en otros términos, la obligación de aceptar la razón o bien descartarla de lleno, de pronunciarse sin más en favor o contra de ella, impide justamente una historia crítica de la racionalidad (1999a, p. 316-317). 
Ahora bien, ¿qué implica ubicarse en las fronteras?, ¿cómo pensar semejante posición? Todo aquello que se ubique en las fronteras estará como salido de sí mismo; no permanecerá ni completamente adentro, pero tampoco completamente afuera. Para el quehacer filosófico que emerge desde la Aufklärung, será el intento de ubicarse en filo de la propia actualidad. Foucault sostendría que la filosofía moderna, al menos la que pregunta por nuestro presente, la que lleva adelante la denominada ontología de nosotros mismos, jamás pertenece a esta u otra época. Lo que tiene de moderno es más bien un modo específico de relación con la actualidad: "El fenómeno que he puesto de relieve y que me parece que ha fundado toda una forma de reflexión filosófica no concierne si no al modo de relación reflexiva con el presente" (Foucault, 1999b, 346). No dejará de llamar la atención el hecho de que Foucault defina la Modernidad como algo más que una simple "época". En efecto, el quehacer filosófico moderno evade los planteos longitudinales o evolutivos, donde solo se procuraría resolver el valor del tiempo presente en relación con el pasado y el futuro. ¿Fue la Antiguiedad mejor o peor que la Modernidad?, ¿hay que definir esta última como un tiempo de decadencia o de progreso? Más que reconocerse en tales planteamientos, la filosofía moderna irrumpe, se da como acontecimiento; hasta cierto punto, emerge de la Aufklärung en tanto modo singular de interrogación sobre el presente. Por eso también, "la filosofía moderna es la que intenta responder la pregunta lanzada, hace dos siglos, con tanta imprudencia: Was ist Aufklärung?" (Foucault, 1999b, p. 336). Si bien resulta cierto que la pregunta se plantea en un determinado momento histórico, lo es igualmente que las respuestas evitan cualquier posicionamiento de esa índole. Se hace ontología del presente asumiendo una posición límite, parándose en las fronteras de la Aufklärung, y no recibiéndola como algo ya establecido o simplemente dado.

Decimos que ubicarse en las fronteras implica pensar más allá de cualquier secuencia o sucesión histórica; quizá convenga añadir ahora que en las fronteras siempre se elige, que no hay posición límite sin una tarea selectiva y viceversa. Hacer ontología del presente es una cuestión de elección; consiste en seleccionar de entre las innumerables posibilidades o tendencias emergentes de la Aufklärung. No otra cosa hace Foucault: "si la cuestión kantiana era saber qué límites debe renunciar a franquear el conocimiento, me parece que la cuestión crítica, hoy en día, se debe tornar cuestión positiva: en lo que se nos da como universal, necesario obligatorio, ¿qué parte hay de lo que es singular, contingente y debido a constricciones arbitrarias? Se trata de transformar la crítica ejercida en la forma de la limitación necesaria en una crítica práctica en forma del franqueamiento posible" (1999b, pp. 347-348). La ontología no se ubica a favor o en contra de la Aufklärung, nunca pretende 
justificarla o rechazarla de manera total y definitiva. Ocurre más bien que de la Aufklärung toma esto y deja de lado esto otro; realiza con ella y desde ella una tarea más positiva. Entonces, Was ist Aufklärung?

En Kant y a partir de Kant, es la salida de una minoría de edad; salida que el hombre alcanza al liberarse del "prejuicio" y la "superstición". Distinta, aunque no por ello completamente opuesta, sería la cuestión para Foucault. Antes que la búsqueda de un límite universal y necesario, un límite que libere al hombre como sujeto autónomo y racional, la Aufklärung posibilita la crítica del poder: "es a la vez el análisis histórico de los límites que se nos han establecido y el examen de su franqueamiento posible" (Foucault, 1999b, p. 351). Así pues, tanto Kant como Foucault encontrarán en la Aufklärung una suerte de salida, pero a condición de asignarle cada uno diferentes alcances e implicaciones. En el primer caso, la salida pasará por la determinación de las estructuras formales de nuestro entendimiento: será la definición de aquello que podemos conocer, que debemos hacer y que nos cabe esperar en tanto sujetos racionales (Kant, 2000, p. 92). En segundo caso, se investigarán los diversos acontecimientos que nos han conducido a constituirnos como sujetos históricos; en otras palabras, lo que habrá de plantearse ahora es por qué conocemos, actuamos y pensamos de esta manera y no de otra. Kant procura salir del estado en el cual se encuentran los hombres -es decir, de la denominada minoría de edad-, señalando un límite universal y necesario; Foucault realiza un movimiento inverso: parte desde los estados a primera vista universales e infranqueables, para señalar que en el límite ellos son el producto de unas azarosas prácticas de poder.

Dos posibles respuestas ante la cuestión de la Aufklärung. A nosotros nos corresponde advertir enseguida que de allí se siguen también dos formas distintas de hacer posible la salida. Porque, en efecto, una cosa es señalar por dónde se

6 Así se entenderá en el breve artículo “¿Qué es la Ilustración?”, donde Kant deja entrever, además, que el prejuicio y la superstición suponen el uso ilegítimo, extralimitado, de la razón. Al rebasar sus límites constitutivos, ya sea por prejuicio o por superstición, la razón se torna heterónoma, queda a merced de una autoridad externa. Esto vale especialmente para la superstición, que aparecería cuando los hombres se representan a la naturaleza como no estando sometida bajo las leyes de su propio entendimiento. Kant encontrará allí, en la extralimitación de la razón, la causa de la pasividad; o si se quiere, aquello por lo cual los hombres continúan aún en la minoría de edad: "la ceguera a la que conduce la superstición, y que impone incluso como obligada, da a conocer la necesidad de ser conducido por otros y, por tanto, más que nada, el estado de una razón pasiva““(2005, p. 29). 
sale, y otra decir cómo se sale; de un lado se describe, mientras que del otro, en cambio, se prescribe. Resulta interesante que tanto para Kant como para Foucault la salida requiera de todo un "trabajo propio" (Kant, 2005, p. 27), o bien de un "trabajo de nosotros mismos sobre nosotros mismos" (Foucault, 1999b, p. 349). Sin embargo, el punto de partida y el fin de semejante trabajo no son en ningún caso los mismos, y es que, siempre en límite, la Aufklärung seguirá emergiendo como una cuestión de elección.

\section{El TRABAJO NUESTRO SOBRE NOSOTROS MiSMOS}

Abordemos nuevamente esa cuestión, pero esta vez desde un ángulo complementario. Was ist Aufklärung? A fines del siglo XVIII, Kant buscaba la salida de una "autoculpable" [selbstverschuldeten] minoría de edad. La minoría de que aquí se trata no debe confundirse nunca con una suerte de impotencia natural, ni tampoco la supuesta infancia de la humanidad. Se trata más bien de una manera de comportarse; es la situación característica de la actualidad y no un condicionamiento impuesto por la naturaleza. La minoría de edad nace en la "actitud" que los hombres tienen para consigo mismos y para con los otros. De ahí que Kant la califique también como un estado autoculpable: "La pereza y la cobardía son las causas de que una gran parte de los hombres permanezca, gustosamente, en minoría de edad a lo largo de su vida, a pesar de que hace tiempo la naturaleza los liberó de dirección ajena [naturaliter majorennes]; y por eso es tan fácil para otros erigirse en sus tutores. ¡Es tan cómodo ser menor de edad!” (2005, p. 21). Cuando los hombres devienen perezosos y cobardes, cuando son incapaces de conducirse a sí mismos, dan lugar a que otros hablen, actúen y piensen por ellos ${ }^{7}$. En última instancia, el estado de minoría de edad no solo está lejos de ser un condicionamiento natural, sino que de hecho ni siquiera es el resultado de violencias o de imposiciones artificiales. Para que la minoría de edad exista y subsista, bastará únicamente con que los hombres se sientan cómodos en su situación actual, asignando a otros la supervisión de todo asunto referido al entendimiento, el conocimiento y la moral.

Foucault retomará las respuestas de Kant, aunque sin necesidad de pronunciarse a favor o en contra de ellas; antes bien, su tarea consistirá en llevarlas hasta una frontera insospechada. Tan es así que ahora introduce la Aufklärung en todo un

Así sucedería con el libro, el director espiritual y el médico, que sustituyen respectivamente al entendimiento, la conciencia moral y los saberes propios: "Si puedo pagar, no tengo necesidad de pensar; otros asumirán por mí tan fastidiosa tarea" (2005, p. 21). 
juego entre el "gobierno de sî" y el "gobierno de los otros": "Gobierno de sí, gobierno de los otros: el estado de minoría de edad se caracteriza sin duda en esa relación, esa relación viciada. (...) Por consiguiente, lo que la Aufklärung debería hacer, lo que está haciendo, es redistribuir las relaciones entre gobierno de sí y gobierno de los otros" (Foucault, 2011, pp. 49). La nueva redistribución gubernamental solo surgirá mediante un cambio de actitud; solo y únicamente a condición de que los hombres modifiquen su relación con la actualidad y consigo mismos. Precisamente allí, en la actitud y en el estado actual de las actitudes, Kant descubriría la causa y, a la vez, el posible camino de salida de la minoría de edad: "ella no yace en la carencia del entendimiento, sino en la falta de decisión y valor para servirse por sí mismo de él sin la guía de otro. ¡Sapere aude! ¡Ten valor de servirte de tu propio entendimiento! He aquí la divisa de la Ilustración” (2005, p. 21).

La actitud como causa y además como objeto de prescripción; como el punto sobre el cual los hombres deben trabajar de manera voluntaria, dándose a sí mismos el lema o la divisa que los conducirá hacia la salida de su autoculpable minoría de edad. No cabe duda de que Foucault distribuirá las cosas de otra manera: en lugar de hablar sobre la supuesta minoría de edad, investigará los modos históricamente singulares que asume el gobierno de los otros; y antes de prescribir el uso legítimo y universal del entendimiento, trabajará más bien en los límites de esto que ya somos. Para verlo en detalle, planteemos la cuestión una vez más, Was ist Aufklärung?

Con Kant y a partir de Kant, será la Crítica como prescripción escrita y llevada adelante en mayúscula: "Desbordar los límites críticos y ponerse bajo la autoridad son las dos vertientes de aquello contra lo cual Kant se levanta en la Crítica, aquello de lo cual el proceso mismo de la Aufklärung debe liberarnos" (Foucault, 2011, p. 47). Con Foucault y su tarea de selección, será en cambio la ontología histórica de nosotros mismos, o la crítica practicada en minúscula; al fin de cuentas, la ontología de las minucias: "esta crítica no es trascendental, y no tiene como meta hacer posible una metafísica: es una crítica genealógica en su finalidad y arqueológica en su método" (Foucault, 1999b, p. 348). La arqueología como método y la genealogía como finalidad: he aquí la principal divisa de Foucault. De su puesta en marcha se sigue algo más que una mera descripción histórica de nosotros mismos. Diríase que la cuestión consiste en señalar la contingencia de este presente nuestro, aquel desde el cual hablamos, actuamos y pensamos. La genealogía viene a desencajarnos, a ponernos en nuestros propios límites. Si se vuelca sobre las prácticas y las relaciones de poder, no es con la sola finalidad de describir los diversos acontecimientos que nos condujeron hasta aquí, sino también para advertir que el poder -y todo lo que 
de antemano iría unido a él, como el error, la mentira y la maldad, todo lo que pertenecería a un pasado oscuro y lejano- nos constituye como esto que ahora somos. Pero justamente por esto, porque somos el producto de unas prácticas inestables de poder, tenemos ahora "la posibilidad de ya no ser, hacer o pensar lo que somos, hacemos o pensamos" (Foucault, 1999b, p. 348).

En el límite, o en ese espacio donde se abre la posibilidad de ya no ser lo que estamos siendo, la ontología deviene tan descriptiva como creativa. Foucault hablará del trabajo nuestro sobre nosotros mismos; trabajo que emergería desde el corazón de la propia Aufklärung: "el principio de una crítica y de una creación permanente de nosotros mismos en nuestra autonomía (...) está en el corazón de la consciencia histórica que la Aufklärung ha tenido de sí misma" (1999b, p. 347). La crítica de nosotros mismos, y la simultánea creación de nosotros como principio de la Aufklärung: haciéndonos de ese principio, seleccionándolo y llevándolo adelante, lograremos abrirnos paso entre las relaciones de poder; todavía más, saldremos hacia una relación completamente distinta a las primeras. En medio del poder, la relación de sí consigo mismo; o también, la fuerza afectándose a sí misma, convirtiéndose en su propio principio de gobierno ${ }^{8}$. El principio de la Aufklärung es, por lo tanto, nuestro, más que de cualquier otro; para nosotros, implicará una nueva diferenciación ante el gobierno de los otros.

No solo se trata de establecer cierta relación con el presente; la cuestión no consiste únicamente en llevar adelante un quehacer filosófico más preocupado por el nosotros actual que por las verdades universales; además de ello, o junto con todo ello, se trata de establecer un modo de relación consigo mismo. ¿Por qué un "modo" de relación y no una relación a secas? Pues bien, porque en lugar de aceptarnos como aquello que somos actualmente, tenemos que trabajarnos y, en lo posible, modificarnos. Según Foucault, la Aufklärung está indisolublemente ligada al "ascetismo": "ser moderno no implica aceptarse a símismo tal como se es en el flujo de los momentos que transcurren; es tomarse a sí mismo como objeto de una elaboración compleja y dura" (1999b, p. 344). Lo que en principio era una tarea para el presente, emerge ahora, desde el corazón de la Aufklärung, como un arduo trabajo de sí sobre sí. ¿Pero por qué hablar de un “trabajo emergente”? La

8 Como bien señalaba Deleuze, si el poder se define como una relación de fuerzas, si resulta inseparable de la capacidad de afectar a otras fuerzas, cabría pensar entonces en una relación donde la fuerza se afecte a sí misma: "surge una relación de la fuerza consigo misma, un poder de afectarse a sí misma, un afecto de sí por sí misma (2008, p. 132). 
Aufklärung no es un código moral o un reglamento de comportamiento que recibimos del pasado; en modo alguno se trata de una receta ya hecha, ya practicada y probada, que como tal deberemos seguir al pie de la letra. El trabajo de sí sobre sí se definiría más bien como una actitud permanentemente renovada, siempre ubicada en sus propios límites: "Con 'actitud' quiero decir un modo de relación respecto a la actualidad, una elección voluntaria efectuada por algunos, así como un modo de obrar y de conducirse que, a la vez, marca una pertenencia y se presenta como una tarea. Un poco, sin duda, como aquello que los griegos llamaban un ethos" (Foucault, 1999b, p. 341-342). Un poco de ethos griego en la modernidad; esto es, prescindiendo de toda división entre las épocas históricas; pero además, un ethos que solo se lleva adelante mediante el trabajo y la elaboración de sí mismo.

¿Hay que suponer aquí, en las prácticas y los trabajos de sí, una suerte de retorno al "sujeto"? Si así lo fuere, cabría decir entonces que las crisis y los silencios de Foucault son un mero intento de corregir los errores cometidos; como si en lugar de ir hasta el límite, no habría tenido más opción que volver sobre sus propios pasos. Para salir del poder, Foucault habría necesitado restituir al sujeto que tanto cuestionara en otro momento; reconstruir y salvar un sujeto en este presente contingente, atravesado por las prácticas de poder. ¿Es esa y nada más que esa la salida que Foucault nos propone? Sin duda que no, porque Foucault jamás habla de retornos ni de restituciones, sino más bien de creaciones; no hace una filosofía del sujeto, sino una ontología de las subjetivaciones ${ }^{9}$. La práctica filosófica que Foucault propone servirá para liberarnos de cualquier sujeto fijo o detenido en sí mismo: "el objetivo principal en estos días no es descubrir lo que somos, sino rechazar lo que somos. (...) Debemos fomentar nuevas formas de subjetividad mediante el rechazo del tipo de individualidad que se nos ha impuesto durante varios siglos" (Foucault, 1988, p. 11). La cuestión no consiste en descubrir aquello que somos, ni tampoco en rescatar algo que el poder siempre querría quitarnos; antes bien, el trabajo de sí sobre sí mismo, el que emerge de la Aufklärung, conduce continuamente hacia la elaboración y reelaboración de nuevos modos de subjetivación. A estas alturas, parecería redundante señalar que la ontología asume una tarea sumamente difícil, una tarea límite: la de fomentar la emergencia de otro nosotros. Que de nuestro trabajo salga

$9 \quad$ Nuevamente, parafraseamos aquí las ilustrativas palabras de Deleuze: "Se dice ahora que Foucault ha vuelto al sujeto, que ha vuelto a descubrir la noción de sujeto que siempre había rechazado. Pero no hay nada de eso. Su pensamiento atravesó, ciertamente, una crisis en todos los órdenes, pero fue una crisis creativa, no un simple arrepentimiento“ (2002, p. 113). 
lo otro, lo actualmente imposible e impensable, lo que aún no puede pensarse en nuestra situación presente.

Con Foucault y la ontología de Foucault, la actitud de la Aufklärung siempre parecería ir más lejos, tanto como para ubicarse en las fronteras de sí misma. En otras palabras, no solo se aplica sobre los límites establecidos por el poder, sino también sobre el modo que actualmente intentamos diferenciarnos del poder. Es precisamente en este punto donde el trabajo de sí deviene en una crítica de sí; para Foucault, sería la crítica de nosotros mismos como seres constituidos mediante la actitud de la Aufklärung: "Hay que intentar hacer el análisis de nosotros mismos en muestra condición de seres históricamente determinados, en cierta medida, por la Aufklärung" (1999b, p. 346). El ser moderno se constituye a sí mismo diferenciándose del poder, abriendo el gobierno de sí entre el gobierno de los otros, mientras que la ontología realiza la crítica de tal legado crítico -esto es, de los diferentes modos en que llevamos adelante la tarea de gobernarnos a nosotros mismos-. De ahí que el trabajo nuestro no conduzca necesariamente hacia un sujeto fijo, libre de críticas; muy por el contrario, se trata de criticarnos hasta en nuestras actuales diferenciaciones con el poder, o de hacer también la ontología de la relación de sí consigo mismo.

De la Aufklärung proviene una cuestión siempre desdoblada o, mejor dicho, triplicada: cuestión del presente; aún más, de nuestro presente; y en el límite, del trabajo crítico sobre nosotros mismos. Foucault releerá toda su labor previa en función de esas tres cuestiones; de hecho, hablará ahora de una ontología triple, una tarea que no queda detenida en sus propios escritos e intervenciones, sino que además abre el camino para otras investigaciones futuras: "la ontología histórica de nosotros mismos tiene que responder una serie abierta de cuestiones, se ha de ocupar de un número no definido de investigaciones que es posible multiplicar y precisar tanto como se quiera (...): ¿cómo nos hemos constituido como sujetos de nuestro saber?; ¿cómo nos hemos constituido como sujetos que ejercen o sufren relaciones de poder?; ¿cómo nos hemos constituido como sujetos morales de nuestras acciones?" (1999b, p. 350). Para nosotros, los que hablamos hoy desde Foucault, los que asumimos la tarea de seleccionar entre sus palabras y sus escritos, este último punto adquiere la mayor importancia. Al fin y al cabo, allí se juega la posibilidad de una ontología sobre los actuales modos de gobernarse a sí mismo. Esta es la ontología que hoy nos hace más falta, la que debemos llevar adelante para ser otros que nosotros mismos. 


\section{Hacer la crítica a la Crítica. NeOliberalismo y SUbJetividad}

Preguntemos nuevamente: ¿qué sucedió durante el largo silencio posterior a la publicación de La voluntad de saber -ese silencio "crítico" que acaecería en los últimos años de Foucault? Pues bien, "Había que pasar por el enraizamiento estráticoestratégico para llegar al pliegue ontológico" (Deleuze, 2008, p. 148). En crisis y en silencio, se pasa desde el poder hacia el trabajo nuestros sobre nosotros mismos. Entre ambas cuestiones reemergerá la Aufklärung, o en palabras de Foucault: "la permanente reactivación de una actitud; es decir, de un ethos filosófico que podría caracterizarse como crítica permanente de nuestro ser histórico (1999b, p. 345). Se pasa, e incluso se sale de toda la cuestión, reactivando la actitud de la Aufklärung, tomado esto y dejando de lado aquello otro.

¿Pero cómo podríamos reactivar nosotros la actitud crítica de Foucault?, ¿qué selección haríamos aquí? Hay una opción perfectamente lícita y sin duda importante en nuestros días. Lo que podríamos hacer es tomarnos el trabajo de ampliar las investigaciones sobre las prácticas de sí greco-romanas, aquellas que Foucault presenta al salir de su largo silencio y que se explayan en los textos El uso de los placeres y La inquietud de sí. El trabajo en cuestión no consistiría en una simple descripción histórica, sino más bien, y como ya advirtiera Foucault, en problematizarnos a nosotros mismos (2003, pp. 16-18). Se trata de analizar las diferentes prácticas mediante las cuales hemos llegado a constituirnos como sujetos de nuestra conducta moral; es sin duda una ontología del presente. Ahora bien, existen en el límite otras opciones, todas ellas también surgidas de la ontología.

Durante el camino de salida, Foucault se encuentra con algo bastante inquietante, un acontecimiento que parecería comprometer completamente nuestros actuales modos de subjetivación. Así lo daría a entender en ciertos cursos y conferencias, aunque sin profundizar demasiado en el asunto; hablando más bien al pasar, o como si estuviese justamente en vías de salida ${ }^{10}$. Nosotros partiríamos, entonces, desde allí, de las problematizaciones que Foucault planteara un poco antes de remitirse por entero hacia las prácticas de sí greco-romanas.

10 Nos referimos a dos textos recogidos a fines de la década de los setenta. El primero, que llevaría por título"Nuevo orden interior y control social", es producto de una conferencia brindada en la Universidad de Vincennes hacia el año 1978; mientras que el otro, que se titularía Nacimiento de la biopolítica, forma parte del curso dictado el siguiente año, en el marco del Collège de France. 
Justo antes de la salida, aparece la pregunta por las especificidades y las diferencias constitutivas del actual "orden interior": "es muy importante para nuestra vida, para nuestra existencia y para nuestra individualidad -en función de lo que queramos hacer-, saber en qué aspectos este orden que vemos instalarse actualmente es realmente un orden nuevo, cuáles son sus especificidades y qué lo diferencia de lo que podría ser el orden de los regímenes precedentes" (Foucault, 1991, pp. 163164). De alguna manera, Foucault vislumbra la alteración y la gradual modificación de la dimensión pública; precisamente aquella donde Kant encontraba la posibilidad de ilustrarse a sí mismo, usando la propia razón sin relación de obediencia o de autoridad: "resulta posible que el público se ilustre a sí mismo, algo que es casi inevitable si se le deja en libertad" (2005, p. 22). ¿De dónde nace el "público" si no es de todo un trabajo de sí sobre sí mismo, y qué otra cosa implica si no la crítica al poder y los poderes instituidos? El público se constituye mediante todo un juego de diferenciaciones con el poder; de hecho, emerge como la crítica contra las extralimitaciones y los abusos de aquel ${ }^{11}$. Frente a un poder abusivo y amenazante, un público siempre atento y vigilante. Esa división tan moderna, tan de fines del siglo XVIII, se reaviva y redistribuye en nuestra actualidad; vale decir, reemerge ahora con nuevos términos y actores.

De un lado estaríamos nosotros, el público capaz de constituirse y de actualizarse a sí mismo mediante la crítica; del otro, el Estado, intrínsecamente defectuoso, mal

11 Según Kant, la razón puede usarse de dos maneras distintas: de manera pública o bien privada. El "uso público" de la razón nos constituye como sujetos universales; o en los términos de Kant, como "doctos" capaces de atener el propio juicio a la razón total de la humanidad: "Entiendo por uso público de la razón el que alguien hace de ella en cuanto docto (Gelehrter) ante el gran público del mundo de los lectores“"(2005, p. 23). El uso privado de la razón se ubicará en un terreno distinto: no es el que hacemos como miembros del público, en cuanto doctos que hablan a la razón total de la humanidad, sino más bien como miembros pasivos del Estado(Kant, 2005, p. 23). En el primer caso, la razón se obedece a sí misma; en el segundo, se acomoda a los fines establecidos por el gobierno de los otros. Así por ejemplo, un hombre está obligado a pagar los impuestos que le son asignados como ciudadano del Estado, ya sin plantear la más mínima crítica ante tal carga; sin embargo, ese mismo hombre puede manifestar sus críticas en cuanto docto, señalando al público los inconvenientes o las injusticias de todo el sistema tributario. Foucault dirá que la diferentes maneras de usar la razón, donde se obedece al poder en cuanto ciudadano y se lo critica en cuanto docto, abren una nueva labor para la actividad filosófica: "desde Kant el papel de la filosofía ha sido el de impedir que la razón sobrepase los límites de lo que está dado en la experiencia; pero desde esta época -con el desarrollo de los Estados modernos y la organización política de la sociedad-el papel de la filosofía también ha sido el de vigilar los abusos del poder de la racionalidad política" (2008c, p. 96). 
constituido, demasiado tradicional o poco adaptado a estos tiempos, pero retornando siempre como una entidad omnipresente y avasallante. La ontología de Foucault sostendrá que el Estado se percibe hoy, en nuestros actuales modos de crítica, como un "fantasma paranoico y devorador": "podríamos decir que lo que se pone en cuestión en la actualidad, y a partir de horizontes extremadamente numerosos, es casi siempre el Estado; el Estado y su crecimiento indefinido, el Estado y su omnipresencia, el Estado y su desarrollo burocrático, el Estado con los gérmenes de fascismo que conlleva, el Estado y su violencia intrínseca debajo del paternalismo providencial..." (2008b, p. 218). Actualmente, gran parte del público percibiría que la más mínima acción estatal es susceptible de convertirse en la más terrible amenaza. Unos hablan de intervenciones autoritarias, otros de fascismo, algunos ligan ambas cosas con el comunismo, mientras que la mayoría supondría que el Estado, ya sea por derecha o por izquierda, ya por defecto o por omisión, se encuentra siempre próximo a degenerar en lo peor.

Las tendencias políticas que hasta la primera mitad del siglo XX quedaban perfectamente separadas, aparecen desde hace cierto tiempo como elementos continuos. Se trataría de una sola línea evolutiva, una relación de parentesco cuyo punto de arranque residiría en el Estado y los aparatos estatales: "el Estado administrativo, el Estado benefactor, el Estado burocrático, el Estado fascista, el Estado totalitario, todos (...) son -según los análisis- las ramas sucesivas de un mismo árbol que crece en su continuidad y su unidad y que es el gran árbol estatal" (Foucault, 2008b, p. 219). Del Estado y de las estructuras estatales, de su inactual burocracia y paternalismo, nos llegarían entonces las peores amenazas, tales como el fascismo e incluso el totalitarismo. Ante esas amenazas, nosotros pasamos a calificarnos y a constituirnos como un público crítico, con el espíritu presto para detectar cualquier germen de fascismo, sumiendo al otro -al político tradicional, al jefe de partido, al representante de Estado, etcétera-en "una descalificación general por lo peor" (Foucault, 2008b, p. 220). Calificarnos como público crítico y descalificar al otro como fascista; todavía más: quitarnos el fascismo de encima, no solo el que germina en el Estado, sino también aquel que logró penetrar en nosotros mismos mediante una larga relación con las obsoletas estructuras estatales. A fines de la década de los setenta, Foucault sostenía que ese modo de relación de sí consigo mismo se encontraba bastante generalizado, tanto como para convertirse en el lugar más común de crítica. He aquí entonces nuestro actual modo de crítica, el que anteponemos al poder, y a toda la inactualidad que conllevaría el poder. Pero he aquí, sin duda y por mucho que nos cueste, la posibilidad de hacer una crítica de nuestra crítica. 
La cuestión no está ciertamente desprovista de dificultades, ni tampoco de enormes riesgos. Después de todo, ¿quién se atrevería a contradecir al público -sobre todo a ese que asume la tarea de detectar la incompetencia, el abuso del poder, y en última instancia la amenaza de fascismo? Foucault señalaba una pauta nada más que inicial: "los que participan en la gran fobia al Estado, sepan bien que están siguiendo la corriente y que (...) por doquier se anuncia desde hace años y años una disminución efectiva del Estado, de la estatización y de la gubernamentalidad estatizante y estatizada" (2008b, p. 225) ${ }^{12}$. Aquellos que encuentran en el Estado y en las políticas estatales la amenaza más grande de todas -sea el germen de fascismo, de totalitarismo y demás tendencias supuestamente "parecidas"- están tan a la corriente que ni siquiera experimentan la especificidad o la dirección particular del caudal que los arrastra. Foucault diría que la "fobia antiestatal" redunda en toda una elisión de la actualidad: "estos análisis permiten evitar pagar el precio de lo real y lo actual (...). Basta con encontrar, a través de la sospecha y (...) de la "denuncia" algo parecido al perfil fantasmático del Estado para que ya no sea necesario analizar la actualidad" (2008b, pp. 220-221). Lo primero por señalar, entonces, es que las denuncias contra el Estado no se ubican en los límites de su propia actualidad, sino que asumen en todo caso una posición más cómoda.

En primer lugar, piensan el presente como un momento diferente, una salida que se lleva adelante mediante la tarea crítica, pero solo bajo la condición de descalificar todo lo que no encaje con ella. En segundo lugar, entienden que cuanto se aparte de la tarea asumida resulta obsoleto o poco adaptado a estos tiempos, tanto que recibe ahora la descalificación de "inactual". Por último, perciben que la supervivencia de lo inactual en el presente no implica otra cosa más que una "amenaza" para ese mismo presente, pues trastoca sus coordenadas y sus diferencias constitutivas. De ahí la facilidad y la intercambiabilidad del análisis. De ahíque el Estado y las diferentes políticas estatales adquieran hoy una suerte de "perfil fantasmático". Como bien sabemos, el fantasma tiene una existencia muy particular: debería pertenecer al pasado, y, sin embargo, no quiere quedarse en el pasado; está en todas partes y, a la vez, en ninguna; al fin y al cabo, solo puede existir como amenaza. Ahora bien,

12 Sobre la disminución efectiva del Estado, que Foucault denominará como "desinversión" o como economización en el ejercicio del poder, véase la conferencia titulada "Nuevo orden interior y control social (1991, pp. 164-165). Sobre la "fobia al Estado" cabe consultar nuestro artículo "La fobia al Estado como remedio espiritual. Incisiones foucaultianas sobre el neoliberalismo". En Perspectivas Metodológicas N. ${ }^{\circ} 15$, Remedios de Escalada, Ediciones de la UNLa, 2015. En este artículo, de próxima aparición, continuamos profundizando las investigaciones abiertas por Foucault. 
poco hay para arriesgar y eventualmente perder cuando nos contentamos con denunciar la inactualidad del otro; cuando de buenas a primeras suponemos que el problema de la actualidad reside en la persistencia de ciertos elementos pertenecientes al pasado.

Precisamente a este, a nuestro actual modo de crítica, habría que plantearle una cuestión sumamente difícil: "la crítica del dinamismo del Estado no efectúa su propia crítica ni su propio análisis. (...) no busca saber de dónde viene realmente esa especie de sospecha antiestatal (...) que circula hoy en tantas formas diversas de nuestro pensamiento" (Foucault, 2008b, p. 221). ¿De dónde procede entonces la crítica contra el dinamismo y el poder estatal? Cuestión sin duda difícil, no solo por la singularidad de su planteo, sino porque, en el límite, trastocaría las actuales divisiones entre el gobierno de sí y el gobierno de los otros.

La genealogía advertiría que nuestros modos de crítica emergen de un momento histórico concreto: las décadas de los treinta y los cuarenta del siglo XX. De hecho, y para complicar aún más las cosas, señalará que proceden de la selección o la tarea que algunos asumieron en aquel momento. Se trata del "neoliberalismo" o, en términos más precisos, de quienes se reunieron inicialmente bajo tal divisa:

la crítica del dinamismo intrínseco y en apariencia irreprimible delEstado, la crítica de las formas estatales que encajan entre sí, se llaman unas a otras, se apoyan (...) y se engendran de manera recíproca, la encontramos ya formulada de manera concreta, perfecta y muy clara en los años 1930-1945 (...). En esa época no tenía la fuerza de circulación que tiene en nuestros días. Se la encontraba muy localizada dentro de las elecciones neoliberales que se formulaban en ese momento (2008b, p. 221) ${ }^{13}$.

13 Queda por demás claro que Foucault no está pensando en cualquier neoliberalismo, al menos no en el que conocemos actualmente y que solemos asociar con la restauración de las viejas teorías liberales, con la desregulación total del mercado, o bien con la violencia y la decadencia de los Estados capitalistas: "El neoliberalismo no es Adam Smith; el neoliberalismo no es la sociedad mercantil; el neoliberalismo no es el gulag en la escala insidiosa del capitalismo" (2008b, p. 157). Para Foucault se trata de otra cosa. La percepción del Estado como una entidad polimorfa, omnipresente y avasallante, la idea de que este tiene un dinamismo irrefrenable, que comenzaría con la planificación económica y que terminaría en el totalitarismo, nace un poco antes dela Segunda Guerra Mundial.Fue en ese particular momento que un puñado de economistas y sociólogos alemanes asumieron la tarea de refundar la economía de mercado y desde allí la sociedad toda. La tarea emerge en la década de los treinta, especialmente alrededor de las figuras de Franz Böhm y Walter 
El neoliberalismo es el lugar de donde procede gran parte de nuestras actuales críticas; es un modo de diferenciarnos ante el poder y de constituirnos a la par como público crítico. Así pues, habría que pasar por ese lugar para vislumbrar la novedad y la diferencia del actual orden interior ${ }^{14}$.

Sin embargo, el propio público sostendría hoy que el neoliberalismo no tiene, ni llegaría a tener nunca, nada de novedoso o de diferente: "desde un punto de vista político, el neoliberalismo es solo la cobertura de una intervención generalizada y administrativa delEstado, tanto más gravosa porque resulta insidiosa y se enmascara bajo la apariencia de un neoliberalismo" (Foucault, 2008b, p. 156). Estamos habituados a escuchar este tipo de crítica; para un sector cada vez más considerable del público, el neoliberalismo solo sería apariencia, mecanismo de manipulación y de engaño. Más que de nosotros, continúa tratándose del otro; más que un trabajo de sí, se trataría de un intervencionismo estatal que cambia de nombre pero no de esencia. Foucault señalaba que las críticas contra el neoliberalismo no permiten hacer nada con él, "salvo prorrogar una y otra vez el mismo tipo de crítica" (2008b, p. 156). Tal vez lo que se prorrogue sea la elección que el neoliberalismo hizo en su momento y que circularía después con tanta fuerza.

Al neoliberalismo se le juzga en gran parte con sus propios términos, jugando su propio juego, presentándolo como la cobertura de una irrefrenable violencia estatal, o como la "ideología" tras la cual subyace el fascismo de Estado. No vamos a negar

Eucken; continúa en la revista Ordo, publicada durante la década siguiente; y es asumida luego por otras personalidades más heterogéneas, como Alexander Rüstow, Wilhelm Röpke, Alfred Müller Armack y Ludwig Erhard, entre otros. El presente del cual se quería salir era, por supuesto, el nazismo, donde los neoliberales alemanes encontraban la muestra más cabal de la relaciones necesarias entre la planificación, el intervencionismo de estilo keynesiano, el socialismo de Estado y el totalitarismo; mientras que el lugar hacia el cual se proponía ir era aquello que, a grandes rasgos, llegó a denominarse como "Economía social de mercado" (Bilger, 1964).

14 Siguiendo las cuestiones que Foucault plantea en su momento, nosotros hemos intentado "pasar" por el neoliberalismo en varias oportunidades. Aquí solo mencionaremos dos textos ya publicados y que están disponibles actualmente en la web. El primero se titula "Edmund Husserl en el ordoliberalismo alemán. Extrañezas, resonancias y actitudes". En Valenciana. Estudios de filosofía y letras, nueva época, año 7, N. ${ }^{\circ}$ 13, Guanajuato, Universidad de Guanajuato, pp. 145-172; el otro lleva el nombre de "El sujeto económico del neoliberalismo. Aportes y discusiones para una nueva 'ontología del presente'". En Hybris. Revista de filosofía, vol. 5, N. ' 1, Santiago de Chile, CENALTES, pp. 33-55. 
aquí las múltiples violencias de las políticas neoliberales, puesto que ellas generan y, en última instancia, admiten toda clase de excesos; tampoco restaremos valor a las críticas y a las simultáneas resistencias ante las situaciones instauradas o legitimadas por el neoliberalismo. Ahora bien, hay que hacer algo más con él y sobre todo contra él. A fines de la década de los setenta, Foucault planteaba la necesidad de comprender la especificidad histórica del neoliberalismo. Esa tarea sigue aún hoy vigente; sobre todo cuando las elecciones neoliberales se han diseminado y generalizado hasta tal punto que ya ni siquiera las apreciamos como aquello que fueron en sus comienzos.

El neoliberalismo es inicialmente la elección mediante la cual un sector del público crítico, un grupo de “doctos", procuró diferenciarse de los poderes existentes. Quizá por eso Foucault no lo problematice a la manera tradicional-vale decir, a la manera de un sujeto crítico que se posiciona frente a un objeto de crítica-. Quizá porque las elecciones neoliberales son hasta cierto punto un modo de constituir sujetos y objetos, o de diferenciar al público del Estado, convenga elaborar otras críticas posibles, que no solo nos hablen sobre la violenta imposición de tal o cual doctrina económica ${ }^{15}$. Si Foucault ha realizado o cuanto menos esbozado otra crítica posible contra el neoliberalismo, cierto es que esta no se desarrolla según los términos habituales. La cuestión consistiría más bien en percibir allí una elección; un modo de trabajarse y gobernarse a sí mismo que puede ser criticado desde dentro, en sus condiciones históricas de emergencia y de funcionamiento ${ }^{16}$.

Así pues, y más allá de que Foucault se lo haya propuesto en forma explícita o no, cabe sugerir que una de las aristas posibles de su crítica iría en esa dirección: sería una crítica practicada desde dentro hacia afuera, desde aquello que ahora somos

15 Bien lo decía Thomas Lemke: "Paradójicamente, la propia crítica al neoliberalismo cae también ella en modelos de argumentación económica. La noción de gubernamentalidad es útil para corregir el diagnóstico que concibe el neoliberalismo como una extensión de la economía al campo político, y que da por sentada la separación entre el Estado y el mercado" (2004, p. 15).

16 Coincidimos aquí con las palabras del filósofo colombiano Santiago Castro-Gómez: "Es en este sentido que se debe leer la afirmación de Foucault de 'no emitir ningún juicio de valor' respecto al neoliberalismo. (...) No es que sus análisis sean 'acríticos' y políticamente neutros, sino que buscan examinar y entender a fondo en qué consiste la racionalidad del neoliberalismo. Y recordemos que para Foucault mostrar cómo funciona una racionalidad de gobierno equivale a mostrar los vacíos a partir de los cuales emergen las subjetividades desobedientes" (2010, p. 187). 
hacia otra cosa que nosotros mismos ${ }^{17}$. Porque, en efecto, el neoliberalismo no emerge ni funciona como algo ajeno a nosotros, sino que en tanto elección y modo de constitución subjetiva tiene que ver con nosotros.

\section{CONSIDERACIONES FINALES}

El tratamiento del neoliberalismo como elección, como una relación de sí consigo mismo, desestabiliza las actuales críticas; incluso más: por el solo acto de desestabilizar, entreabre la posibilidad de otro trabajo o tarea. Es sin duda el uso que Foucault pretendía hacer de la historia; el de disociar gradualmente nuestra identidad: "La historia (...) no tiene como meta encontrar las raíces de nuestra identidad, al contrario, se empeña en disiparla; no intenta descubrir el hogar único del que venimos (...); intenta hacer aparecer todas las discontinuidades que nos atraviesan" (Foucault, 2004, pp. 67-68). Las elecciones neoliberales son una de las tantas discontinuidades que nos atraviesan -bien puede que la más fuerte y tajante, bien al menos la que resulta hoy más desconcertante-. Tornando manifiesta esa discontinuidad, iremos haciéndonos discontinuos a nosotros mismos.

Nadie quiere mezclarse hoy con el neoliberalismo; nadie, ni aquellos que critican ni quienes reciben la (des)calificación de neoliberales, está dispuesto a rebajarse de tal forma. Mas la crítica a la crítica advertiría que somos herederos de una elección cuyos efectos y alcances se vuelven difíciles de calificar u objetivar. El neoliberalismo no es un mero objeto puesto frente a nosotros, los sujetos críticos. Antes bien, hay allí algo más oscuro e inquietante, acaso una inesperada y casi impensable amenaza.

Esa amenaza no viene simplemente de los otros, sino que emerge de nosotros, de lo que somos hoy por herencia: "la herencia (...) es un conjunto de fallas, de fisuras, de capas heterogéneas que la hacen inestable y que, desde el interior o desde abajo, amenazan al frágil heredero" (Foucault, 2004, p. 28). Cuando la amenaza emerge desde adentro y desde abajo, muy poco nos queda para salvar y defender. La crítica a la crítica, o el recorrido por lo más bajo -entiéndase bien, por el

17 ¿Qué podríamos ser en los límites y, si se quiere también, más allá del neoliberalismo? Esta es una cuestión que permanece aún abierta y que, como tal, resulta imposible de contestar en el marco del presente artículo; de hecho, es una cuestión perteneciente al terreno de la "invención” política. Debemos inventar una nueva articulación entre el gobierno de sí y el gobierno de los otros, que ya no estécondicionada o dirigida por las elecciones que el neoliberalismo introdujera en su momento. 
neoliberalismo - tiende a convertirnos en herederos frágiles y despojados de casi todo; pero, recíprocamente, con la posibilidad de trabajarse y de transformarse a sí mismos.

Que a nosotros no nos quede nada, esto es, que no tengamos más opción que comenzar a ser otros: "Al sujeto nunca le 'queda' nada, puesto que constantemente hay que crearlo como núcleo de resistencia” (Deleuze, 2008, p. 138). De ahí una de las posibles tareas que recibimos hoy de Foucault. Se trata de hacer la crítica a nuestros actuales modos de crítica, introduciendo en ellas -es decir, en nosotros mismos-la discontinuidad y el acontecimiento. Se trata de pasar por el neoliberalismo, por sus críticas, sus elecciones y sus trabajos, para que ya no nos quede nada de él; para salir de lo que ahora estamos siendo.

\section{REFERENCIAS}

Bilger, F. (1964). La pensée économique libérale dans l'Allemagne contemporaine. París: Librairie Générale de droit et de jurisprudence.

Castro-Gómez, S. (2010). Historia de la gubernamentalidad. Razón de Estado, liberalismo y neoliberalismo en Michel Foucault. Bogotá: Siglo del Hombre Editores.

Deleuze, G. (2002). Conversaciones. Madrid: Editorial Nacional.

Deleuze, G. (2008). Foucault. Buenos Aires: Paidós.

Eribon, D. (1992). Michel Foucault. Barcelona: Anagrama.

Foucault, M., (1988). "El sujeto y el poder". Revista Mexicana de Sociología, Vol. 50, N. ${ }^{\circ}$, pp. 3-20.

Foucault, M. (1991). "Nuevo orden interior y control social”. En: Saber y Verdad (pp. 163-166). Madrid: La Piqueta.

Foucault, M. (1992). “Verdad y poder”. En: Microfísica del poder (pp. 185-200). Madrid: La Piqueta.

Foucault, M. (1999a). "Estructuralismo y posestructuralismo”. En: Ética, estética y hermenéutica. Obras esenciales, Volumen III (pp. 307-334). Barcelona: Paidós. 
Foucault, M. (1999b). “QQué es la Ilustración?’. En: Ética, estética y hermenéutica. Obras esenciales, Volumen III (pp. 335-352). Barcelona: Paidós.

Foucault, M. (2002). La arqueología del saber. Buenos Aires: Siglo XXI.

Foucault, M. (2003). Historia de la Sexualidad II. El uso de los placeres. Buenos Aires: Siglo XXI.

Foucault, M. (2004). Nietzsche, la genealogía, la historia. Valencia: Pre-textos.

Foucault, M. (2007) ، 'La vida: la experiencia y la ciencia”. En: Giorgi, G. y Rodríguez, F. Ensayos sobre biopolítica. Excesos de vida (pp. 41-57). Buenos Aires: Paidós.

Foucault, M. (2008a). "La vida de los hombres infames". En: La vida de los hombres infames (pp. 121-138). Buenos Aires: Altamira.

Foucault, M. (2008b). Nacimiento de la biopolítica. Curso en el Collège de France (1978-1979). Buenos Aires: Fondo de Cultura Económica.

Foucault, M. (2008c). "Omnes et singulatim: hacia una crítica de la "razón política"”. En: Tecnologías del yo y otros textos afines. Buenos Aires: Paidós, pp. 95140.

Foucault, M. (2011). El gobierno de sí y de los otros. Curso en el Collège de France (1982-1983). Buenos Aires: Fondo de Cultura Económica.

Kant, I. (2000). Lógica. Un manual de lecciones. Madrid: Akal.

Kant, I. (2005). “¿Qué es la ilustración?”. En: Ensayos sobre la paz, el progreso y el ideal cosmopolita (pp. 21-31). Madrid: Cátedra.

Lemke, T (2006). “Marx sin comillas': Foucault, la gubernamentalidad y la crítica del neoliberalismo". En: Marx y Foucault (pp. 5-20). Buenos Aires: Nueva Visión. 